Published in final edited form as:

ACS Infect Dis. 2017 March 10; 3(3): 190-198. doi:10.1021/acsinfecdis.6b00209.

\title{
A Sensitive In Vitro High-Throughput Screen to Identify Pan- Filoviral Replication Inhibitors Targeting the VP35-NP Interface
}

\author{
Gai Liu' ${ }^{1,2}$, Peter J. Nash², Britney Johnson ${ }^{1}$, Colette Pietzsch ${ }^{3}$, Ma. Xenia G. Ilagan ${ }^{4}$, \\ Alexander Bukreyev ${ }^{3}$, Christopher F. Basler ${ }^{5}$, Terry L. Bowlin ${ }^{2}$, Donald T. Moir ${ }^{2}$, Daisy W. \\ Leung $^{1}$, and Gaya K. Amarasinghe ${ }^{1}$ \\ ${ }^{1}$ Department of Pathology and Immunology, Washington University School of Medicine, St Louis, \\ MO 63110, United States \\ ${ }^{2}$ Microbiotix Inc, 1 Innovation Drive, Worcester MA 01605, United States \\ ${ }^{3}$ Department of Pathology, Department of Microbiology and Immunology, and Galveston National \\ Laboratory, University of Texas Medical Branch at Galveston, Galveston, TX 77555, United States \\ ${ }^{4}$ High Throughput Screening Center, Department of Biochemistry and Molecular Biophysics, and \\ Department of Developmental Biology, Washington University School of Medicine, St Louis, MO \\ 63110, United States
}

${ }^{5}$ Center for Microbial Pathogenesis, Institute for Biomedical Sciences, Georgia State University, Atlanta, Georgia 30303, United States

\begin{abstract}
The 2014 Ebola outbreak in West Africa, the largest outbreak on record, highlighted the need for novel approaches to therapeutics targeting Ebola virus (EBOV). Within the EBOV replication complex, the interaction between polymerase co-factor, viral protein 35 (VP35), and nucleoprotein (NP) is critical for viral RNA synthesis. We recently identified a peptide at the N-terminus of VP35 (termed NPBP) that is sufficient for interaction with NP and suppresses EBOV replication, suggesting that the NPBP binding pocket can serve as a potential drug target. Here we describe the development and validation of a sensitive high throughput screen (HTS) using a fluorescent polarization assay. Initial hits from this HTS include the FDA approved compound tolcapone, whose potency against EBOV infection was validated in a non-fluorescent secondary assay. High conservation of the NP/VP35 interface among filoviruses suggest that this assay has the capacity to identify panfiloviral inhibitors for development as antivirals.
\end{abstract}

\section{Keywords}

Ebola virus; nucleoprotein; VP35; fluorescence polarization assay; high-throughput screening

\footnotetext{
Corresponding authors: Gaya K. Amarasinghe, gamarasinghe@wustl.edu; Daisy W. Leung, dwleung@wustl.edu; Donald T. Moir, dmoir@microbiotix.com.

SUPPORTING INFORMATION The Supporting Information is available free of charge via the Internet at http://pubs.acs.org/.
} 


\section{INTRODUCTION}

Filoviruses, including Ebolavirus and Marburgvirus, belong to the family Mononegavirales, which includes non-segmented negative-sense RNA viruses ${ }^{1}$. They are causative agents of severe hemorrhagic fever and associated with case fatality rates up to $90 \%$ in human patients $^{2}$. The most recent 2014 outbreak in West Africa was the largest in history with over 28,000 confirmed cases and over 11,000 deaths related to EBOV infection according to the $\mathrm{WHO}^{3}$. While there are many promising vaccine candidates ${ }^{4-5}$ and a monoclonal antibody ${ }^{6-7}$ mediated therapy that look promising, currently no approved efficacious and safe treatments are available against EBOV infection (CDC. Treatment of Ebola Hemorrhagic Fever. Available from: http://www.cdc.gov/vhf/ebola/treatment). For example, ZMapp, a mixture of three monoclonal antibodies that showed initial efficacy against Ebola infection in rhesus macaques ${ }^{8}$, did not show high potency as expected in a randomized and controlled trial in human subjects ${ }^{9}$. Thus, a potent and safe treatment is urgently needed. The most advanced approaches for anti-filovirus therapy, with demonstrated effectiveness in nonhuman primates (NHPs), utilize RNA interference (RNAi), mixtures of monoclonal antibodies, or repurposed influenza, herpes, respiratory syncytial (RSV), or hepatitis C $(\mathrm{HCV})$ virus inhibitors ${ }^{10}$. However, the efficacy of these agents remains unproven; furthermore, many were developed for other viruses and may suffer from limited potency against filoviruses. In addition, the biologics (antibodies, RNAi) are expensive, difficult to store and administer in the field, and act in a viral species-specific manner, which will necessitate stockpiling multiple agents to cover all known virulent filoviruses, or reducing their effectiveness in outbreaks caused by new viral species.

The viral replication complex is an attractive target for drug development because of its essential role in viral pathogenesis. Small molecules that inhibit the formation and/or functions of the viral replication complex are desirable as these would restrict viral infection and spread. The EBOV viral genome encodes for seven open reading frames, of which nucleoprotein (NP), viral protein 35 (VP35), and L (the RNA-dependent RNA polymerase), are required for viral replication in the cytoplasm ${ }^{11-12}$, along with VP30 for transcription. VP35 is thought to bridge the interaction between L and NP, which encapsidates the viral genome $^{11-13}$. We have previously identified a minimal NP-binding peptide region in EBOV VP35, called NPBP (residues 20-48), that is required for interaction with $\mathrm{NP}^{14}$. This interaction between VP35 NPBP and NP is critical for viral replication as mutations of residues in VP35 NPBP results in diminished activity in the minigenome assay and overexpression of NPBP leads to suppression of EBOV viral replication in HeLa cells, suggesting the therapeutic potential of targeting the interaction between NPBP and $\mathrm{NP}^{14}$. The availability of the structure of EBOV VP35 NPBP/NP complex along with our studies on the VP35 NPBP/NP interaction provide a framework to design an assay to guide structure-based antiviral development.

Here we describe the development of a binding assay using fluorescence polarization as a platform for high throughput screening of small molecules that target the EBOV replication complex. We used the highly specific interaction between VP35 NPBP and NP to build a fluorescence polarization assay that detects fluorescein-labeled NPBP binding to NP. The assay was miniaturized, optimized, and validated prior to use in a high throughput screening 
format. Our results highlight the high sensitivity of the assay and its potential to identify pan-filoviral inhibitors.

\section{RESULTS AND DISCUSSION}

The EBOV replication complex is minimally comprised of NP, VP35, and the polymerase L, where VP35 bridges the interaction between NP and $\mathrm{L}^{15-16}$ (Figure 1A). The minimal region of VP35 required to bind to the $\mathrm{N}$-terminal domain of $\mathrm{NP}\left(\triangle \mathrm{NP}_{\mathrm{NTD}}\right)$, referred to as the NP binding peptide (NPBP), is highly conserved in filoviruses. Examination of the VP35 $\mathrm{NPBP} / \triangle \mathrm{NP}_{\mathrm{NTD}}$ complex structure (PDB: 4YPI) reveals a large number of intermolecular interactions and surface complementarity between VP35 NPBP and $\triangle \mathrm{NP}_{\mathrm{NTD}}$ that drives specificity and affinity (Figure 1B) ${ }^{14}$. Furthermore, VP35 NPBP binding to $\Delta \mathrm{NP}_{\mathrm{NTD}}$ prevents oligomerization of $\mathrm{NP}^{14}$ and NP-RNA binding, which may be part of a critical mechanism to regulate viral RNA synthesis.

In order to identify inhibitors of this target site, we developed a fluorescence polarization (FP) assay to measure the interaction between NPBP and $\triangle \mathrm{NP}_{\mathrm{NTD}}$. The FP assay has a number of advantages compared to other biophysical and biochemical methods. It does not consume large amounts of proteins or probes, it is free of radioactive labels, homogeneous, and lacks a washing step that could disrupt the interaction between probe and receptor. The FP assay is both, sensitive and robust, and the FP signal is independent of probe concentrations providing useful information about biomolecular interactions. The 29 residue $(\sim 3.2 \mathrm{kDa})$ VP35 NPBP peptide was synthesized alone and with fluorescein isothiocyanate (FITC) conjugation at the $\mathrm{N}$-terminus (Genscript, $\mathrm{NJ}$ ). $\Delta \mathrm{NP}_{\mathrm{NTD}}$ was expressed in E. coli and purified as previously described ${ }^{14}$. Upon excitation with polarized light, free FITC-NPBP emits depolarized light because of its fast molecular rotation (Figure 1C). Binding of the 48 $\mathrm{kDa}$ protein receptor, $\Delta \mathrm{NP}_{\mathrm{NTD}}$, restricts the mobility of FITC-NPBP (Figure 1C), and as a result, bound FITC-NPBP emits relatively more polarized light upon excitation. In addition, fluorescence polarization increases with increasing $\triangle \mathrm{NP}_{\mathrm{NTD}}$ concentration, reflecting increased proportions of bound FITC-NPBP (Figure $2 \mathrm{~A}$ ). The dissociation constant, $\mathrm{K}_{\mathrm{D}}$, calculated from the titration curve is $32 \mathrm{nM} \pm 3 \mathrm{nM}$, consistent with $\mathrm{K}_{\mathrm{D}}$ determined by isothermal titration calorimetry ${ }^{14}$, suggesting that FITC conjugation to the VP35 NPBP does not interfere with the NP-NPBP interactions. Titration of unlabeled NPBP into $1 \mathrm{nM}$ FITC$\mathrm{NPBP}+20 \mathrm{nM} \Delta \mathrm{NP}_{\mathrm{NTD}}$ (black, Figure 2B) demonstrates that NPBP displaces FITC-NPBP from $\Delta \mathrm{NP}_{\mathrm{NTD}}$, with an $\mathrm{IC}_{50}$ of $262 \mathrm{nM} \pm 68 \mathrm{nM}$. Two truncated VP35 NPBP constructs, NPBP mut1 (28-46) and NPBP mut2 (26-48), are also able to outcompete FITC-NPBP for $\triangle \mathrm{NP}_{\mathrm{NTD}}$ with $\mathrm{IC}_{50}$ values higher than that of NPBP (Figure 2B). This is consistent with our ITC data showing that the $\mathrm{K}_{\mathrm{D}}$ values of NPBP mut1 and mut2 are higher than that of $\mathrm{NPBP}^{14}$. However, it is important to note that at high concentrations both NPBP mutants reduced FP signal to the free-probe level similar to the effect of excess wild-type NPBP.

To determine assay sensitivity and to evaluate the potential of FP assays as a tool for HTS, we carried out a small scale FP assay. We measured the FP signals for a series of samples of free FITC-NPBP (red) and bound to $\triangle \mathrm{NP}_{\mathrm{NTD}}$ (blue) and determined a $\sim 190 \mathrm{mP}$ window between positive and negative samples (Figure $3 \mathrm{~A}$ and Table S1). A similar value was also obtained for bound FITC-NPBP with $\triangle \mathrm{NP}_{\mathrm{NTD}}$ (magenta) and in the presence of unlabeled 
NPBP (purple) (Figure 3B and Table S1). The Z'-factor is a statistical parameter used to assess the quality of a HTS assay and it is calculated using equation (4) and with control data ${ }^{17}$. A Z' factor between 0.5 and 1 indicates that the HTS assay is optimized sufficiently to enable the statistically significant identification of inhibitors. The $Z^{\prime}$-factor values for both experiments are above $0.7\left(Z^{\prime}=0.81\right.$ and 0.72 for in Figure 3A and 3B, respectively) demonstrating the robustness of the FP assay.

To further optimize the FP assay parameters, an optimal read height (distance between the microplate and instrument optics) was obtained at which data is collected producing maximum signal. Control samples described previously were collected at read heights (height from the reading plane to the detector) varying between 6 to $11.75 \mathrm{~mm}$. At a read height above $8 \mathrm{~mm}$, desirable maximum Z' values (0.86) were obtained (Figure S1A); and thus, an $8.5 \mathrm{~mm}$ read height was maintained for FP assays.

The effect of probe (FITC-NPBP) concentrations was also determined while keeping the $\Delta \mathrm{NP}_{\mathrm{NTD}}$ protein concentration range constant (Figure S1B). FITC-NPBP probe concentrations over a range of 1 to $10 \mathrm{nM}$ did not significantly affect the observed binding $\mathrm{K}_{\mathrm{D}}$. Similarly, the concentration of $\Delta \mathrm{NP}_{\mathrm{NTD}}$, protein receptor, was optimized. At $\Delta \mathrm{NP}_{\mathrm{NTD}}$ concentration above $20 \mathrm{nM}, Z^{\prime}$ values remain above 0.8. (Figure S1C and S1D). Taken together, high-throughput screening experiments were performed with $1 \mathrm{nM}$ probe (FITC$\mathrm{NPBP})$ and $20 \mathrm{nM}$ protein receptor $\left(\Delta \mathrm{NP}_{\mathrm{NTD}}\right)$.

The FPA was then transferred to a HTS format. A pilot screen was performed on a chemically diverse library of 640 FDA approved drugs to determine utility of the assay in a HTS format. Z' values are above 0.5 ( 0.51 and 0.67 for each assay plate). The separation between positive and negative controls (blue and magenta, respectively) is $\sim 170 \mathrm{mP}$ (Figure 3C). In addition, the majority of test wells (green) show $\mathrm{mP}$ values consistent with the negative control, with relatively few compounds showing significant inhibition/ depolarization. These results demonstrate the robustness of the FPA in a scaled up HTS format and some selectivity for inhibition of the FITC-NPBP/NP interaction.

To determine the reproducibility of the FPA, a second HTS was performed on the same FDA library. In this second screen, the assay again showed Z' values above 0.5 ( 0.78 and 0.79 for each assay plate). Individual $\mathrm{mP}$ values for each well were then converted to $\mathrm{Z}$-scores (number of standard deviations from the average negative control). Negative Z-scores indicate a response less than the average negative control potentially due to inhibition. Plotting the Z-scores for these duplicate sets against each other illustrates excellent reproducibility in the negative and positive control wells (Figure 3D, blue and magenta). In addition, the $\mathrm{Z}$-scores for the screening wells demonstrate a strong linear correlation between both screening sets $\left(R^{2}=0.74\right)$. Based on these results, we conclude that the FPA shows a high level of reproducibility between screening sets.

We implemented an FPA-based counter screen using two host proteins to isolate compounds that are potentially false positives. Nrf2 (nuclear factor erythroid-derived 2-like 2) is a transcription factor, which regulates expression of proteins that protect cells from oxidative stress $^{18}$. The degradation of Nrf2 is controlled by Keap1 (Kelch-like ECH-associated protein 
1), a substrate adaptor protein for the Cul3 E3 ubiquitin ligase. The interaction between Nrf2 and Keap1 have been previously characterized to involve the Nrf Neh2 domain residues ETGE and the Keap1 Kelch domain ${ }^{19}$. In the counter screen, FITC-labeled Nrf2 peptide containing ETGE residues (FITC-ETGE) was used as the probe and the Keap1 Kelch domain, as the protein receptor. Screening the previously described library in the counter screen, a total of seven compounds were identified as initial hits in both FITC-NPBP/ $\Delta \mathrm{NP}_{\mathrm{NTD}}$ and FITC-ETGE/Kelch screens. These compounds were considered false positives and were excluded from downstream confirmation (Table S2).

Of the initial hits, 4 compounds (Figure 4) were further characterization. Trequisin showed no concentration dependent inhibitory effect on FP (blue, Figure 4A). Epinephrine-(+)-L(-) (Figure 4B) and 5-aminosalicylic acid (Figure 4C) disrupted the NP-NPBP interaction at high concentrations with a decrease in FP. However, fluorescence intensity also increased with increasing compound concentration, indicating that intrinsic compound fluorescence likely interferes with FP measurements (green, Figure 4B and 4C). Tolcapone (Figure 4D) showed a more dramatic dose-dependent inhibitory effect with an $\mathrm{IC}_{50}$ of $2 \mu \mathrm{M} \pm 02 \mu \mathrm{M}$, while fluorescence intensity remained relatively the same.

As noted above, a potential limitation of the fluorescence polarization assay is that intrinsic fluorescence of compounds may dominate the FP signals and lead to false positive due to interference. Therefore, we developed an orthogonal non-fluorescence-based secondary assay using biolayer interferometry (BLI) to confirm the initial hits in order to eliminate high background issues associated with autofluorescence. Association of $\triangle \mathrm{NP}_{\mathrm{NTD}}$ to biotinylated NPBP (Bio-NPBP) bound to streptavidin pins was measured in the presence of unlabeled NPBP, Trequinsin, epinephrine-(+)-L(-), 5-aminosalicylic acid, or tolcapone. Figure 5A shows the overlay of a complete cycle, including dissociation, association, and baseline. Tolcapone is the most effective inhibitor of VP35 NPBP/ $\triangle \mathrm{NP}_{\mathrm{NTD}}$ interaction (Figure 5B), consistent with the FP assay data (Figure 4).

We next tested tolcapone against a recombinant EBOV that expresses GFP (EBOV-GFP) ${ }^{20}$ in Vero cells. Vero cells were initially treated with tolcapone at $10 \mu \mathrm{M}$ or DMSO only in the absence of EBOV to rule out effects simply due to cytotoxicity. We found the cell monolayers were still intact four days post treatment (Figure 5C). Therefore, cells were treated with $10 \mu \mathrm{M}$ tolcapone or diluent (DMSO) alone and infected with EBOV-GFP at an MOI of 0.01 or $2 \mathrm{PFU} /$ cell (Figure 5C). Viral titers in the presence of DMSO or tolcapone were quantified by focus-forming assay 3 days post infection (Figure 5C-5D). Tolcapone reduced EBOV titer by $>100$-fold at a MOI of 0.01 and by $>5$-fold at a MOI of 2 . Taken together, these data demonstrate that the FPA HTS is able to identify inhibitors of EBOV replication.

The FPA described above can also be used to identify pan-filoviral inhibitors. The EBOV VP35 residues encompassed by NPBP is highly conserved among members of the Filoviridae family (Figure 6A). When we test binding of the EBOV VP35 NPBP corresponding peptide from three different filoviruses to EBOV $\triangle \mathrm{NP}_{\mathrm{NTD}}$, we find that all filoviral VP35 peptides bind with similar affinities (Figure 6B-E), suggesting that NP binding is a conserved function of VP35. Addition of each of the four compounds identified 
from the FPA HTS for EBOV VP35 NPBP/ $\triangle \mathrm{NP}_{\mathrm{NTD}}$ on the homologous proteins from MARV showed an inhibition pattern similar to that observed for EBOV VP35 NPBP/ $\triangle \mathrm{NP}_{\mathrm{NTD}}$ (compare Figure $6 \mathrm{~F}$ to Figure $5 \mathrm{~B}$ ). Taken together, these results suggest that the FP assay can be applied to targeting panfiloviral protein interactions and that inhibitors that interrupt EBOV NP-NPBP interactions will have similar impact on NP-NPBP interactions across species.

\section{CONCLUSIONS}

The fluorescence polarization assay described here is a robust and reliable assay that can identify inhibitors of Ebola viral replication and potentially function in a panfiloviral manner. From a pilot screen using FPA in a HTS format, we identified an FDA approved drug, tolcapone, whose potency against EBOV infection was confirmed in a cell-based assay. Since it is an existing drug, future studies of tolcapone will involve evaluation of its pan-filoviral activity and confirmation of activity in filoviral animal infection models to determine its safety and efficacy in vivo. Novel inhibitors discovered in the FPA will undergo chemical optimization of potency, selectivity, and drug-like properties to advance them toward therapeutics.

Extension of this assay to other NNSVs, such as human respiratory syncytial virus, as well as Nipah and Hendra viruses, would likely yield a class of inhibitors that can serve as biological probes or therapeutic leads. Because the interaction between viral nucleoprotein and co-factor VP35 of the replication complex is conserved across negative-sense RNA viruses, we envision that this FPA can be used as a tool to screen for small molecule inhibitors of replication of other RNA viruses.

\section{METHODS}

\section{Protein Expression and Purification}

All filoviral proteins and Keap1 Kelch were purified using methods previously described $^{14,21-22}$. Protein purity was assessed by Coomassie staining of SDS-PAGE. All peptides, including VP35 NPBP, FITC-NPBP, Bio-NPBP, Nrf2 ETGE, and FITC-ETGE were purchased from GenScript (Piscataway, New Jersey).

\section{Fluorescence polarization assay development}

Parameter settings-FP assays were performed on Synergy NEO HTS and Cytation5 plate reader from BioTek (Winooski, Vermont) operating with Gen5 Software. Excitation and emission wavelengths were set to 485 and $529 \mathrm{~nm}$, respectively, with a bandpass of 20 $\mathrm{nm}$ for both. Autogain function was selected. 25 reads were collected per well and the read height was set to $8.5 \mathrm{~mm}$. On Synergy NEO, parallel fluorescence and FP signal from a probe-only sample were set to $50000 \mathrm{RFU}$ and $20 \mathrm{mP}$, respectively. On Cytation5, parallel fluorescence from a probe-only sample was set to $50000 \mathrm{RFU}$ and $\mathrm{G}$ factor was optimized following manufacturer guidance (set to 1.26 for most experiments) in order to achieve probe only fluorescence polarization signal of $\sim 20 \mathrm{mP}$. 
Titration experiments-FITC-NPBP at a final concentration of $1 \mathrm{nM}$ was added to protein receptor samples $\left(\triangle \mathrm{NP}_{\mathrm{NTD}}\right)$ prepared with a series of 2-fold dilutions with buffer containing $20 \mathrm{mM}$ Tris (pH 7.5), $150 \mathrm{mM} \mathrm{NaCl}, 2 \mathrm{mM}$ TCEP, and 2\% (v/v) DMSO in a 384-well plate (Corning). After a 10-min incubation, FP signals were measured. FP in millipolarization units $(\mathrm{mP})$ were plotted against protein concentration $(\mu \mathrm{M})$ using Origin software (San Clemente, California). Data were fitted using Equation (2).

Competition experiments-Competitor samples were prepared with a series of 2-fold dilutions. Protein receptor and FITC-NPBP were then added to competitors sequentially. Final protein receptor and FITC-NPBP concentrations used were 20 and $1 \mathrm{nM}$, respectively. Samples were incubated in a 384-well plate at room temperature for $30 \mathrm{~min}$ before data collection. FP signals were plotted against competitor concentration and fitted using Equation (3) in Origin.

Z'-factor determination-FP signals of a total of 24 samples of both positive and negative controls were measured and plotted using Origin. $Z^{\prime}$ values were calculated using Equation (4) ${ }^{17}$.

Data analysis-Fluorescence polarization is calculated automatically by Gen5 software using the following equation:

$$
\mathrm{FP}=\frac{I_{\|}-I_{\perp}}{I_{\|}+I_{\perp}} \quad \text { Equation (1) }
$$

where $I_{\|}$is the parallel fluorescence intensity and $I_{\perp}$ is the perpendicular fluorescence intensity. Titration curves of the protein receptor were fitted using the following equation in Origin:

$F=\left(F_{\text {bound }}-F_{\text {free }}\right) \times \frac{\left(K_{D}+L_{\text {tot }}+R_{\text {tot }}\right)-\sqrt{\left(K_{D}+L_{\text {tot }}+R_{\text {tot }}\right) 2-4 R_{\text {tot }} L_{\text {tot }}}}{2 R_{\text {tot }}}+F_{\text {free }}$ Equation

Where $F_{\text {bound }}$ is the FP when FITC-NPBP is saturated with NP, $F_{\text {free }}$ is the FP of free FITCNPBP, $K_{D}$ is the dissociation constant, $L_{\text {tot }}$ the total ligand/probe concentration, and $R_{t o t}$ the total receptor concentration. Competition data were fitted using:

$$
F=F_{\text {free }}+\frac{F_{\text {bound }}-F_{\text {free }}}{K_{D} \times \frac{C_{\text {tot }}+K_{2}}{K_{2} \times L}+1} \quad \text { Equation (3) }
$$

Where $F_{\text {free }}$ is the FP of free FITC-NPBP, $F_{\text {bound }}$ is the FP of FITC-NPBP saturated with protein receptor, $K_{D}$ is the dissociation constant of FITC-NPBP, $K_{2}$ is the dissociation 
constant of compound/competitor, and $L$ is the concentration of the compound/competitor. $\mathrm{Z}^{\prime}$ is calculated using the following equation ${ }^{17}$ :

$$
Z^{\prime}=1-\frac{3\left(\sigma_{+}+\sigma_{-}\right)}{\left|\mu_{+}-\mu_{-}\right|} \quad \text { Equation (4) }
$$

where $\sigma_{+}$and $\sigma_{-}$are the standard deviation of positive and negative controls, respectively, and $\mu_{+}$and $\mu_{-}$are the FP values of positive and negative controls, respectively.

\section{Fluorescence polarization assay (HTS)}

Automation and Screening Parameters-The pilot HTS was performed using an FDA compound library diluted in DMSO (initial concentration of $250 \mu \mathrm{M}$ ). A Caliper LifeSciences SciClone ALH 3000 was then used to transfer $2 \mu \mathrm{L}$ of compound (final compound concentration of $10 \mu \mathrm{M}$ in the screening wells) or DMSO only (control wells) from these compound plates into black 384-well plates (Corning). A Matrix WellMate was used to add $50 \mu \mathrm{L}$ per well of screen/negative control and positive control master mixes prepared in buffer containing $20 \mathrm{mM}$ Tris (pH 7.5), $150 \mathrm{mM} \mathrm{NaCl}, 2 \mathrm{mM}$ TCEP. Screening and negative control wells had a final concentration of $10 \mathrm{nM}$ FITC-NPBP peptide probe and $20 \mathrm{nM}$ NP receptor. Positive control wells had a final concentration of $1 \mu \mathrm{M}$ unlabeled NPBP in addition to the receptor and probe. Plates were then incubated for 10 minutes at room temperature before being read.

Read Parameters-For HTS, the FPA was performed using a PerkinElmer EnVision 2102 Multilabel Plate Reader equipped with a FITC FP Dual Emission Label. Read parameters on the PerkinElmer Envision were set as follows - read height $9 \mathrm{~mm}$, excitation $480 \mathrm{~nm}$, emission detection $535 \mathrm{~nm}$, excitation energy 100\%, 25 flashes per well. In addition, the gain for both P/S detectors was set to 300 with a G-factor of $\sim 0.61$. These parameters yielded a probe-only sample with values of $\sim 500,000 \mathrm{RFU}$ and $\sim 20 \mathrm{mP}$.

Analysis-RFU and $\mathrm{mP}$ values were automatically calculated by the Perkin Elmer EnVision software as above (see Data analysis). Compounds showing significant inhibition with an $\mathrm{mP}$ z-score of $<-5$ and $\mathrm{P}$ and $\mathrm{S}$ plane RFU values within a z-score of $\mathbf{5}$ with respect to the negative control were selected as hits.

Dose Responses-Hit compounds were cherry picked from $2.5 \mathrm{mM}$ compound stock plates. Dilution series were prepared to yield a $100 \mu \mathrm{M}$ highest concentration in the assay with serial dilutions down to $0.6 \mu \mathrm{M}$. The FPA was performed, read, and analyzed as above.

\section{FITC-ETGE counter screen}

FITC-ETGE studies were carried out for the counter screen following a similar strategy to that described above for FITC-NPBP studies. Briefly, FPA studies were performed on a Cytation5 plate reader using $485 \mathrm{~nm}$ excitation and $528 \mathrm{~nm}$ emission filters appropriate for FITC labelled Nrf2 ETGE peptide (59-LEETGEFL-68). FP assays were performed in 20 $\mathrm{mM}$ Tris $\mathrm{pH}$ 7.5, $150 \mathrm{mM} \mathrm{NaCl}$, and $2 \mathrm{mM}$ TCEP and in black nonbinding surface Corning 
3650 96-well plates. The binding affinity of FITC-Nrf2 ETGE peptide to the Keap1 Kelch domain was determined by titration experiments. Titration experiments were carried out with $2 \mathrm{nM}$ FITC-ETGE peptide and increasing concentrations of the Keap1 Kelch protein ranging from > 1.0E-5 to $50 \mu \mathrm{M}$. Experiments were performed at least in duplicate. FP was determined using Gen5 2.07 analysis software by measuring the parallel and perpendicular fluorescence intensity with respect to linear polarized excitation light. Competition assays were established using conditions described above for $1 \mathrm{nM}$ FITC-Nrf2 ETGE peptide, 40 nM Keap1 Kelch, and varying concentrations of unlabeled Nrf2 ETGE peptide ranging from 0.025 to $100 \mu \mathrm{M}$ in a $100 \mu \mathrm{L}$ volume per well and analyzed using Origin software.

\section{Biolayer interferometry (BLI) binding studies}

BLI competition experiments were performed on an Octet RED from forteBIO. Streptavidin (SA) pins were soaked in wells with biotinylated NPBP at $50 \mathrm{nM}$ for $15 \mathrm{~min}$, washed with buffer for $5 \mathrm{~min}$ and baselined for $1 \mathrm{~min}$. Bio-NPBP loaded SA pins were then moved to wells containing $\Delta \mathrm{NP}_{\mathrm{NTD}}$ at $250 \mathrm{nM}$ premixed with competitors at $10 \mu \mathrm{M} . \Delta \mathrm{NP}_{\mathrm{NTD}}$ alone or compounds was used as the reference to calculate relative response. Buffer contained $20 \mathrm{mM}$ Tris (pH 7.5), $150 \mathrm{mM} \mathrm{NaCl}, 2 \mathrm{mM}$ TCEP, 2\% DMSO, 0.5\% BSA, and 0.02\% Tween 20. BSA and Tween 20 were used to prevent non-specific binding by $\Delta \mathrm{NP}_{\mathrm{NTD}}$ to the streptavidin pins.

\section{Cell culture}

Vero E6 cells were maintained in minimal essential medium (MEM) with 2\% FBS, $0.1 \%$ gentamicin, $1 \%$ nonessential amino acids, and $1 \%$ sodium pyruvate and cultured at $37{ }^{\circ} \mathrm{C}$ and $5 \% \mathrm{CO}_{2}$.

\section{Viruses}

Wild-type Zaire EBOV was previously modified by addition of the transcriptional cassette encoding enhanced green fluorescent protein (eGFP) between the NP and VP35 genes as described $^{20}$, generously provided by Dr. J. Towner and Dr. S. Nichol (CDC).

\section{Infectious assay}

Vero E6 cells were seeded at $2 \times 10^{5} / \mathrm{ml}$ in 24-well plates with minimal essential medium with $10 \%$ bovine fetal serum and $0.1 \%$ gentamycin and incubated overnight. After changing growth media with $2 \%$ fetal bovine serum with gentamicin, cells were treated with either DMSO or Tolcapone in triplicate. At 24 hours post treatment, Vero cells were infected with EBOV-GFP at a MOI of 0.01 or $2 \mathrm{PFU} /$ cell and incubated for 1 hour at $37^{\circ} \mathrm{C}$. Media was aspirated from cells, and cells were washed with PBS. $1 \mathrm{~mL}$ fresh medium with compounds was then added to the wells, and incubated at $37{ }^{\circ} \mathrm{C}$. One hundred microliter aliquots were taken from the supernatant to determine the virus titer using focus-forming assay. One hundred microliters of medium containing DMSO or Tolcapone were added back to each well to maintain the total sample volume. Images were taken to record antiviral effects using the Olympus IX-71 Inverted Fluorescence Microscope, Hamamatsu camera with DCAM driver and HCImage Software. All work with EBOV was performed in the biosafety level 4 (BSL-4) facility of the Galveston National Laboratory. 


\section{Supplementary Material}

Refer to Web version on PubMed Central for supplementary material.

\section{Acknowledgments}

This work was supported by in part by NIH grants R01AI123926 (to GKA and CFB), R01 AI114654 (to GKA, DWL, and CFB), and U19AI109945 (Basler-PI) and P01AI120943 (Amarasinghe-PI) to GKA, MLG, DWL, and CFB.

\section{References}

1. Fields Virology. 5. Lippincott Williams and Wilkins; 2007.

2. Messaoudi I, Amarasinghe GK, Basler CF. Filovirus pathogenesis and immune evasion: insights from Ebola virus and Marburg virus. Nat Rev Microbiol. 2015; 13(11):663-76. [PubMed: 26439085]

3. Misasi J, Sullivan NJ. Camouflage and misdirection: the full-on assault of ebola virus disease. Cell. 2014; 159(3):477-86. [PubMed: 25417101]

4. Choi JH, Schafer SC, Zhang L, Kobinger GP, Juelich T, Freiberg AN, Croyle MA. A single sublingual dose of an adenovirus-based vaccine protects against lethal Ebola challenge in mice and guinea pigs. Mol Pharm. 2012; 9(1):156-67. [PubMed: 22149096]

5. Choi JH, Jonsson-Schmunk K, Qiu X, Shedlock DJ, Strong J, Xu JX, Michie KL, Audet J, Fernando L, Myers MJ, Weiner D, Bajrovic I, Tran LQ, Wong G, Bello A, Kobinger GP, Schafer SC, Croyle MA. A Single Dose Respiratory Recombinant Adenovirus-Based Vaccine Provides Long-Term Protection for Non-Human Primates from Lethal Ebola Infection. Mol Pharm. 2015; 12(8):2712-31. [PubMed: 25363619]

6. Flyak AI, Shen X, Murin CD, Turner HL, David JA, Fusco ML, Lampley R, Kose N, Ilinykh PA, Kuzmina N, Branchizio A, King H, Brown L, Bryan C, Davidson E, Doranz BJ, Slaughter JC, Sapparapu G, Klages C, Ksiazek TG, Saphire EO, Ward AB, Bukreyev A, Crowe JE Jr. CrossReactive and Potent Neutralizing Antibody Responses in Human Survivors of Natural Ebolavirus Infection. Cell. 2016; 164(3):392-405. [PubMed: 26806128]

7. Flyak AI, Ilinykh PA, Murin CD, Garron T, Shen X, Fusco ML, Hashiguchi T, Bornholdt ZA, Slaughter JC, Sapparapu G, Klages C, Ksiazek TG, Ward AB, Saphire EO, Bukreyev A, Crowe JE Jr. Mechanism of human antibody-mediated neutralization of Marburg virus. Cell. 2015; 160(5): 893-903. [PubMed: 25723164]

8. Qiu X, Wong G, Audet J, Bello A, Fernando L, Alimonti JB, Fausther-Bovendo H, Wei H, Aviles J, Hiatt E, Johnson A, Morton J, Swope K, Bohorov O, Bohorova N, Goodman C, Kim D, Pauly MH, Velasco J, Pettitt J, Olinger GG, Whaley K, Xu B, Strong JE, Zeitlin L, Kobinger GP. Reversion of advanced Ebola virus disease in nonhuman primates with ZMapp. Nature. 2014; 514(7520):47-53. [PubMed: 25171469]

9. Group PIW, Multi-National, P. I. I. S. T. A Randomized, Controlled Trial of ZMapp for Ebola Virus Infection. N Engl J Med. 2016; 375(15):1448-1456. [PubMed: 27732819]

10. Madelain V, Nguyen TH, Olivo A, de Lamballerie X, Guedj J, Taburet AM, Mentre F. Ebola Virus Infection: Review of the Pharmacokinetic and Pharmacodynamic Properties of Drugs Considered for Testing in Human Efficacy Trials. Clin Pharmacokinet. 2016

11. Muhlberger E, Lotfering B, Klenk HD, Becker S. Three of the four nucleocapsid proteins of Marburg virus, NP, VP35, and L, are sufficient to mediate replication and transcription of Marburg virus-specific monocistronic minigenomes. J Virol. 1998; 72(11):8756-64. [PubMed: 9765419]

12. Muhlberger E, Weik M, Volchkov VE, Klenk HD, Becker S. Comparison of the transcription and replication strategies of marburg virus and Ebola virus by using artificial replication systems. $\mathbf{J}$ Virol. 1999; 73(3):2333-42. [PubMed: 9971816]

13. Boehmann Y, Enterlein S, Randolf A, Muhlberger E. A reconstituted replication and transcription system for Ebola virus Reston and comparison with Ebola virus Zaire. Virology. 2005; 332(1): 406-17. [PubMed: 15661171] 
14. Leung DW, Borek D, Luthra P, Binning JM, Anantpadma M, Liu G, Harvey IB, Su Z, EndlichFrazier A, Pan J, Shabman RS, Chiu W, Davey RA, Otwinowski Z, Basler CF, Amarasinghe GK. An Intrinsically Disordered Peptide from Ebola Virus VP35 Controls Viral RNA Synthesis by Modulating Nucleoprotein-RNA Interactions. Cell reports. 2015; 11(3):376-89. [PubMed: 25865894]

15. Becker S, Rinne C, Hofsass U, Klenk HD, Muhlberger E. Interactions of Marburg virus nucleocapsid proteins. Virology. 1998; 249(2):406-17. [PubMed: 9791031]

16. Groseth A, Charton JE, Sauerborn M, Feldmann F, Jones SM, Hoenen T, Feldmann H. The Ebola virus ribonucleoprotein complex: a novel VP30-L interaction identified. Virus Res. 2009; 140(12):8-14. [PubMed: 19041915]

17. Zhang JH, Chung TD, Oldenburg KR. A Simple Statistical Parameter for Use in Evaluation and Validation of High Throughput Screening Assays. J Biomol Screen. 1999; 4(2):67-73. [PubMed: 10838414]

18. Copple IM. The Keap1-Nrf2 cell defense pathway--a promising therapeutic target? Adv Pharmacol. 2012; 63:43-79. [PubMed: 22776639]

19. Fukutomi T, Takagi K, Mizushima T, Ohuchi N, Yamamoto M. Kinetic, thermodynamic, and structural characterizations of the association between Nrf2-DLGex degron and Keap1. Mol Cell Biol. 2014; 34(5):832-46. [PubMed: 24366543]

20. Towner JS, Paragas J, Dover JE, Gupta M, Goldsmith CS, Huggins JW, Nichol ST. Generation of eGFP expressing recombinant Zaire ebolavirus for analysis of early pathogenesis events and highthroughput antiviral drug screening. Virology. 2005; 332(1):20-7. [PubMed: 15661137]

21. Edwards MR, Johnson B, Mire CE, Xu W, Shabman RS, Speller LN, Leung DW, Geisbert TW, Amarasinghe GK, Basler CF. The Marburg virus VP24 protein interacts with Keap1 to activate the cytoprotective antioxidant response pathway. Cell reports. 2014; 6(6):1017-25. [PubMed: 24630991]

22. Johnson B, Li J, Adhikari J, Edwards MR, Zhang H, Schwarz T, Leung DW, Basler CF, Gross ML, Amarasinghe GK. Dimerization Controls Marburg Virus VP24-dependent Modulation of Host Antioxidative Stress Responses. J Mol Biol. 2016; 428(17):3483-94. [PubMed: 27497688] 
A

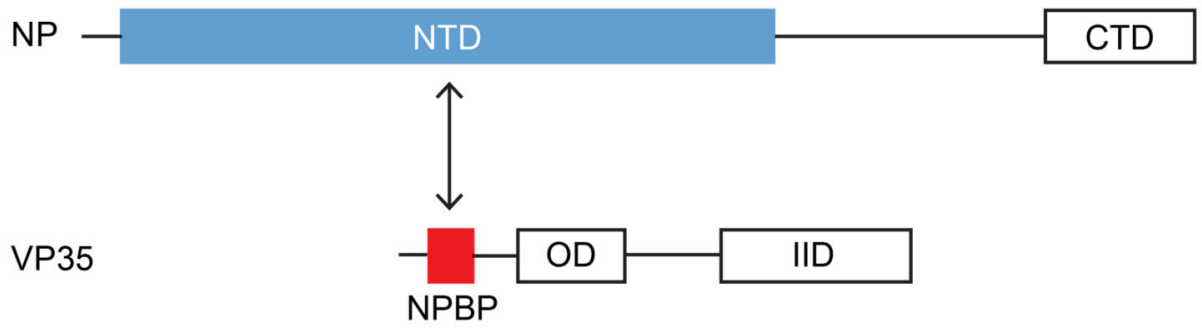

C

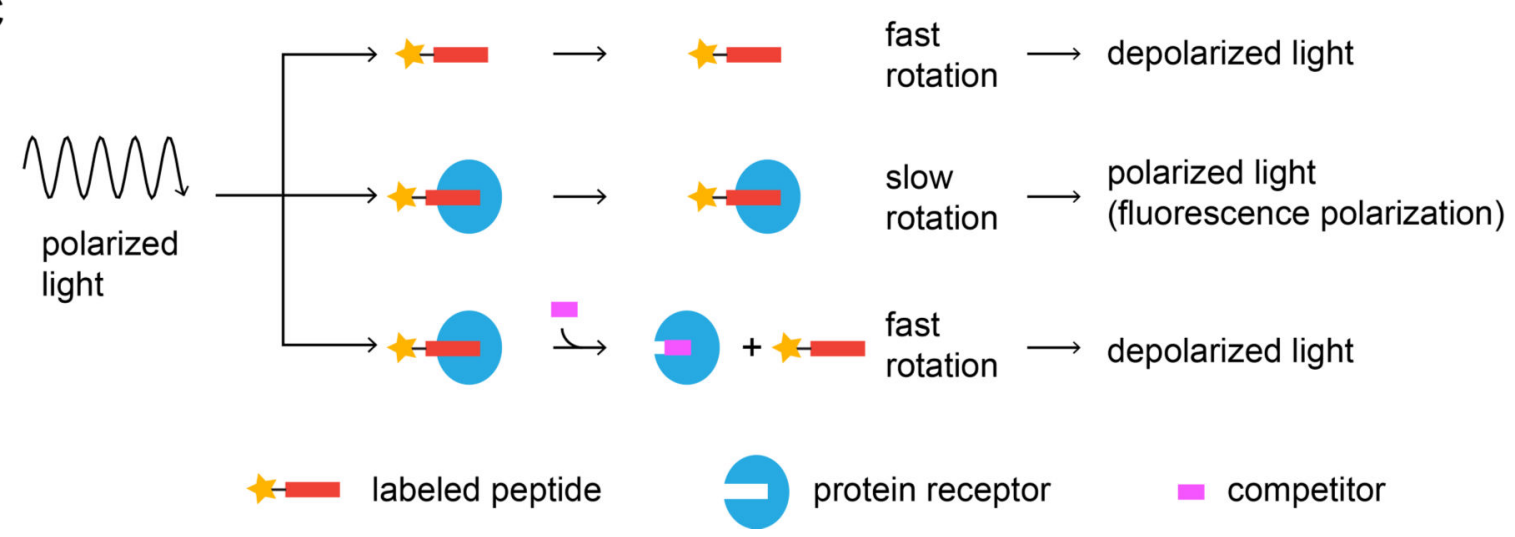

B

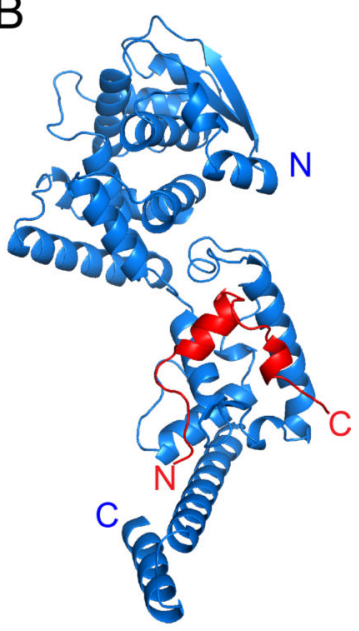

Figure 1.

The EBOV VP35/NP interface is a target for HTS assay development. (A) EBOV RNA synthesis requires viral proteins NP, VP35, and polymerase L. The N-terminal domain (NTD) of NP (blue) binds ssRNA and the VP35 NPBP (VP35 NP binding peptide) (red). The NP C-terminal domain (CTD) is important for viral replication, but the precise function is currently unknown. VP35 oligomerization domain (OD) and interferon inhibitory domain (IID) are labeled as shown. Arrows indicate interactions that are validated at present. (B) Ribbon representation of the crystal structure of the EBOV $\triangle \mathrm{NP}_{\mathrm{NTD}}$ (blue) and VP35 NPBP (red) complex (PDB 4YPI). (C) Schematic of the fluorescence polarization assay based on the NP/NPBP interaction. Outcomes in the polarization assays and the corresponding peptides (NPBP or FITC-NPBP), protein receptor $\left(\Delta \mathrm{NP}_{\mathrm{NTD}}\right)$ and competitor are labeled. 
A

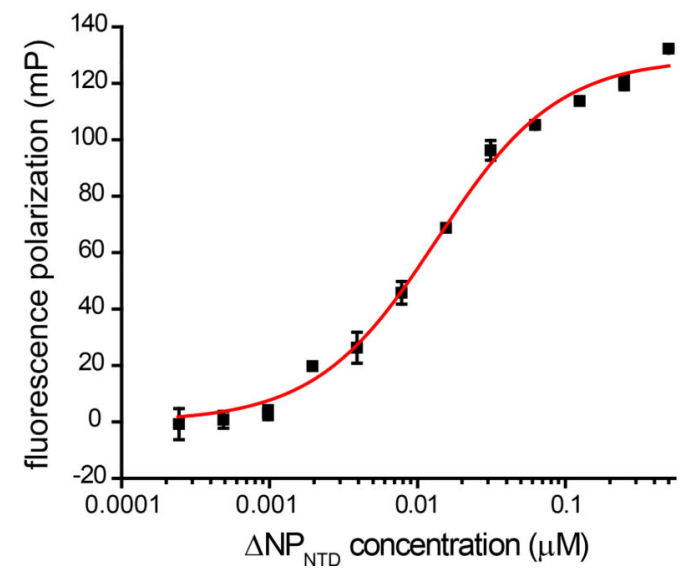

B

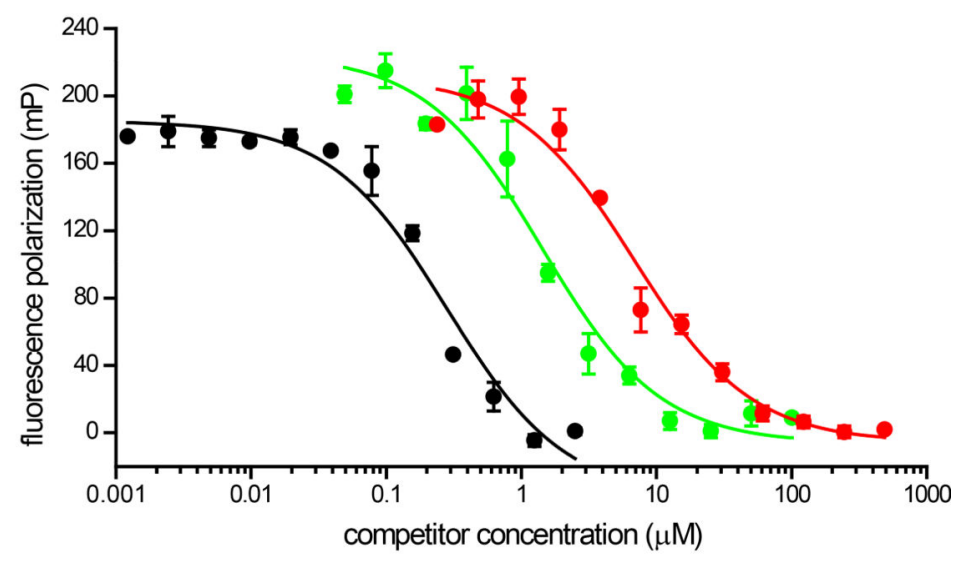

Figure 2.

FITC-NPBP binding to $\triangle \mathrm{NP}_{\mathrm{NTD}}$ results in a highly sensitive FPA with a large dynamic range. (A) Titration with the protein receptor, $\triangle \mathrm{NP}_{\mathrm{NTD}}$, results in an increase in fluorescence polarization of FITC-NPBP peptide. Apparent $K_{D}=32 \pm 3 \mathrm{nM}$ was calculated for FITCNPBP from non-linear fitting (red) using Origin (San Clemente, California). (B) Competition with unlabeled NPBP (black) and NPBP truncation mutants 28-46 (red) and 26-48 (green) with $1 \mathrm{nM}$ FITC-NPBP in the presence of $20 \mathrm{nM} \Delta \mathrm{NP}_{\mathrm{NTD}}$ resulted in apparent dissociation constants of $0.27 \pm 0.07,1.39 \pm 0.36$, and $6.61 \pm 1.47 \mu \mathrm{M}$ for NPBP and NPBP mutants, respectively. 
A

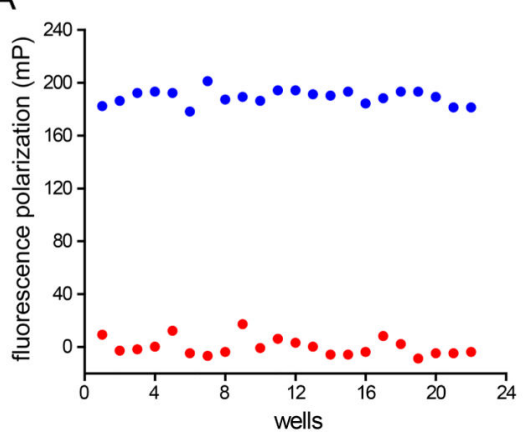

C

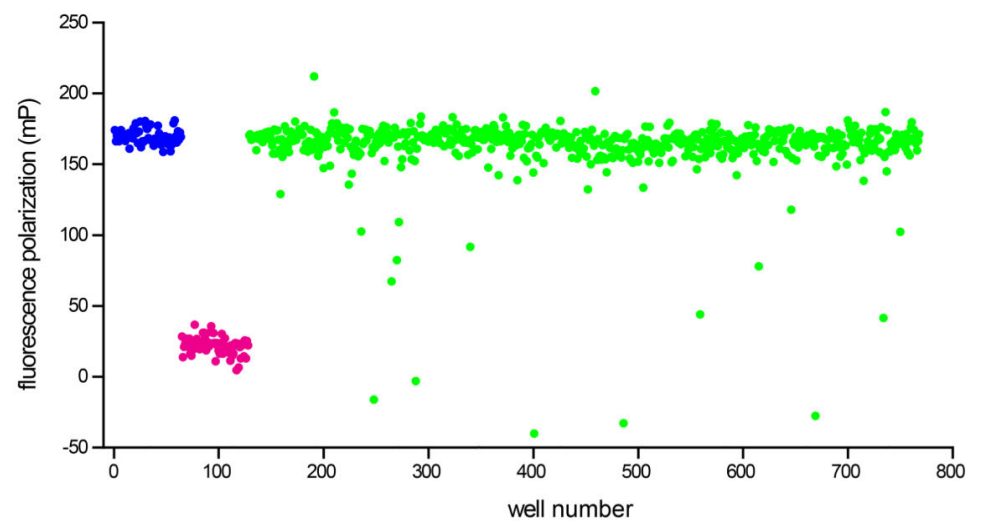

D

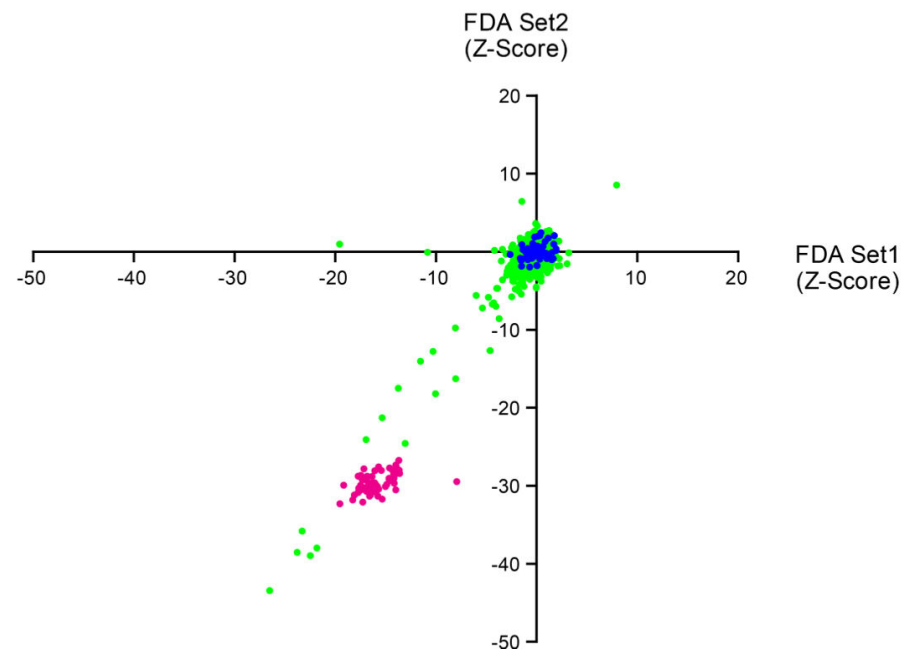

Figure 3.

Results from the initial screens reveals that the assay is highly reproducible. (A) FP signals from 22 samples containing $1 \mathrm{nM}$ free FITC-NPBP (red, positive controls) and with $20 \mathrm{nM}$ $\Delta \mathrm{NP}_{\mathrm{NTD}}$ (blue, negative controls) were used to determine the $\mathrm{Z}^{\prime}$-factor, signal-to-noise ( $\mathrm{S} / \mathrm{N}$ ) and signal-to-background (S/B) ratios, and assay window values using $1 \mathrm{nM}$ probe (FITCNPBP). See Table S1. (B) FP signals of 22 samples of $1 \mathrm{nM}$ FITC-NPBP $+20 \mathrm{nM} \Delta \mathrm{NP}_{\mathrm{NTD}}$ (blue, negative control) and with $1 \mu \mathrm{M} \mathrm{NPBP}$ (magenta, positive control) plotted versus sample wells. (C) Pilot screening using 640 FDA-approved drugs (green). 64 samples of 1 $\mathrm{nM}$ FITC-NPBP $+1 \mu \mathrm{M}$ NPBP with $20 \mathrm{nM} \Delta \mathrm{NP}_{\mathrm{NTD}}$ (magenta) and 64 of nM FITC-NPBP 
with $20 \mathrm{nM} \Delta \mathrm{NP}_{\mathrm{NTD}}$ (blue) are used as positive and negative controls, respectively. (D) Results from duplicate screens of the FDA-approved drugs were converted to Z-scores with respect to the negative control. The correlation coefficient $\left(\mathrm{R}^{2}\right)$ between the duplicate assays is 0.74 . 

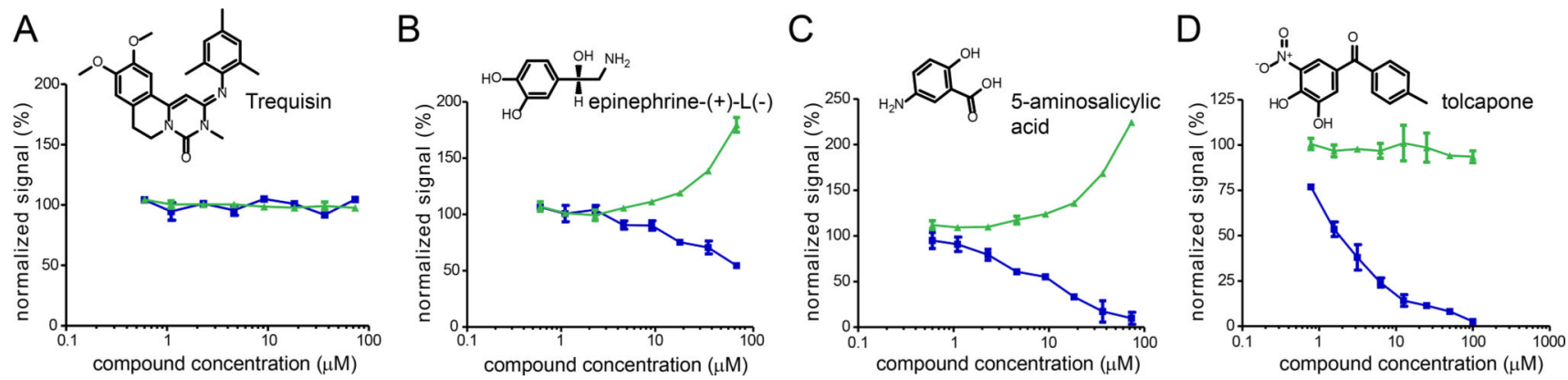

Figure 4.

The NPBP/NP FPA assay identified several hits that show dose-dependent responses.

Representative data for a non-hit (A) and three hits (B-D) are shown where FP (blue) is plotted as a function of compound concentration for: (A) trequinsin, (B) epinephrine- $(+)$ L(-), (C) 5-aminosalicylic acid, and (D) tolcapone. Assay conditions contained $1 \mathrm{nM}$ FITC$\mathrm{NPBP}+20 \mathrm{nM} \Delta \mathrm{NP}_{\mathrm{NTD}}$ with 2-fold dilutions of compounds. Fluorescence intensity is plotted in green. 
A

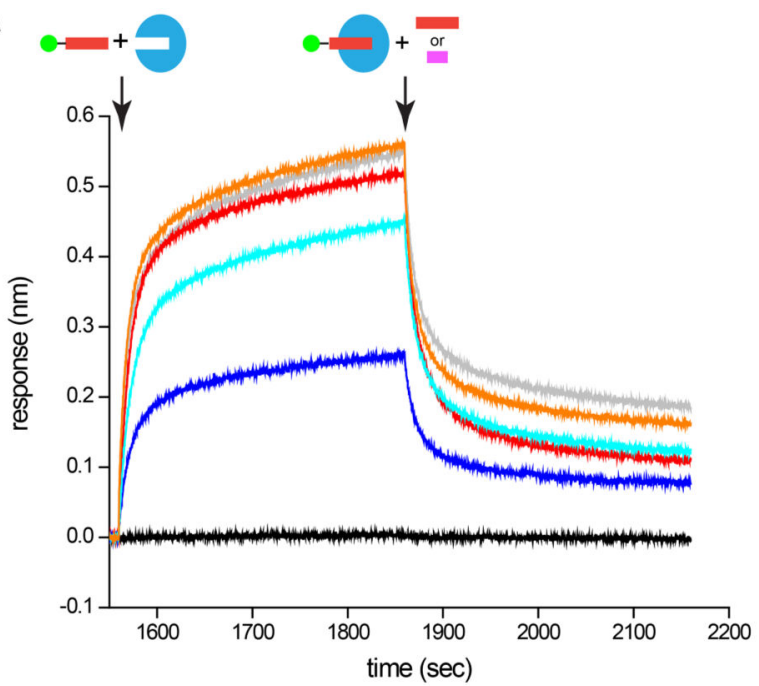

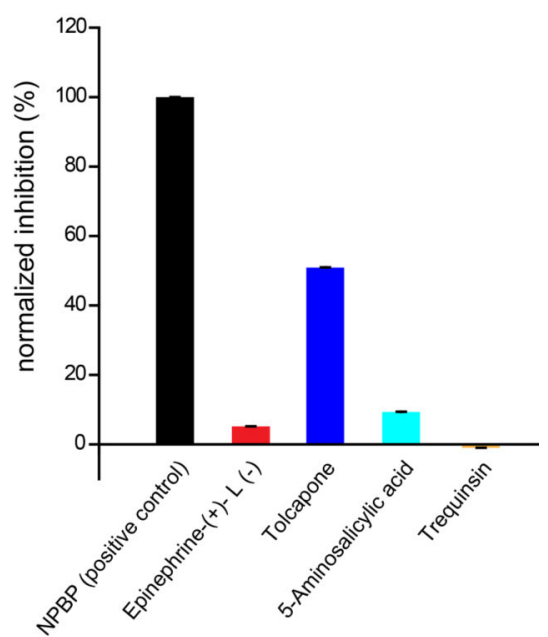

C
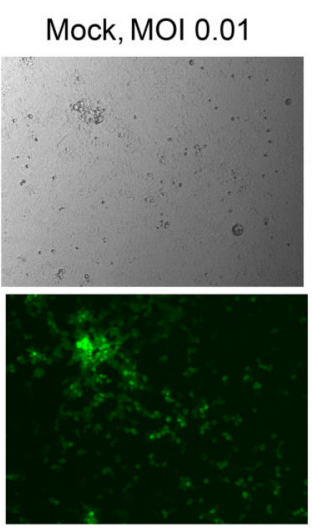

Mock, MOI 2

$10 \mu \mathrm{M}, \mathrm{MOI} 0.01$

$10 \mu \mathrm{M}, \mathrm{MOI} 2$
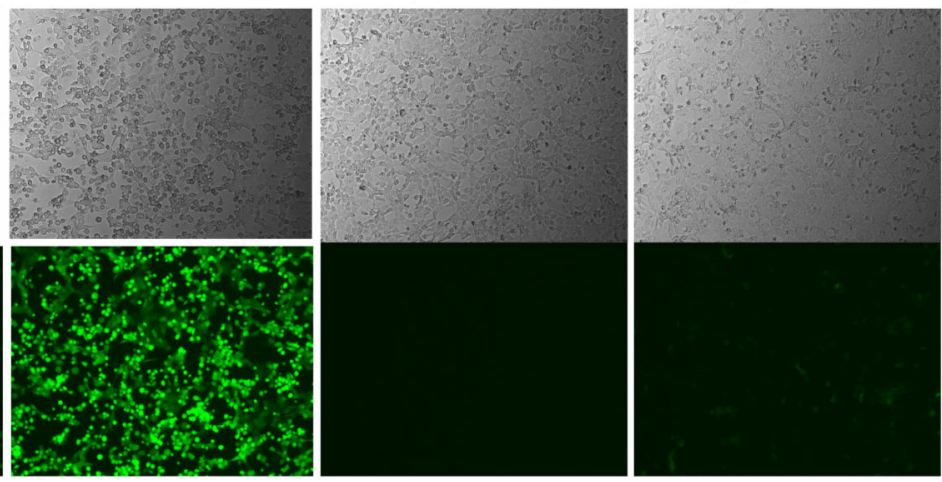

D

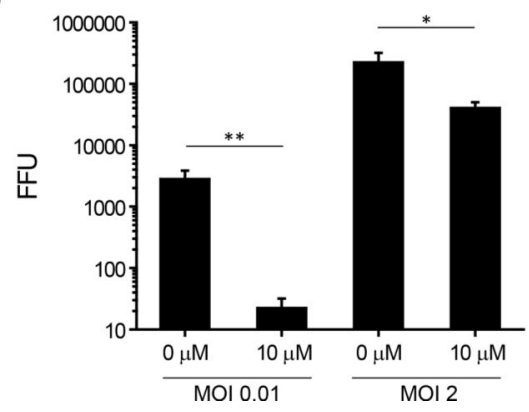

Figure 5.

Validation of compounds identified from FPA with biolayer interferometry (BLI) analysis and infectious assay. (A) BLI analysis of VP35 NPBP binding to $\triangle \mathrm{NP}_{\mathrm{NTD}}$ in the presence of compounds. BLI association and dissociation curves for NPBP (black), epinephrine-(+)-L (-) (red), tolcapone (blue), 5-aminosalicylic acid (cyan), and trequinsin (orange). Baseline curve for DMSO only is shown in gray. (B) Normalized data from (A) at 5 seconds prior to the beginning of dissociation indicated by the arrowhead in (A). $250 \mathrm{nM} \Delta \mathrm{NP}_{\mathrm{NTD}}$ and 10 $\mu \mathrm{M}$ competitor were used in the assays. (C and D) Tolcapone inhibits the infection of Vero cells by EBOV-GFP. (C) Bright-field (top) and fluorescence (bottom) images of EBOV-GFP- 
infected Vero E6 cells treated with DMSO (mock) or Tolcapone at $10 \mu \mathrm{M}$ 4dpi. (D) Viral titers were determined by focus-forming assay $3 \mathrm{dpi}$. Results are in triplicate and plotted as averages and standard deviations. * indicates $\mathrm{p}$ value $<0.030, * * \mathrm{p}$ value $<0.011$. 
A
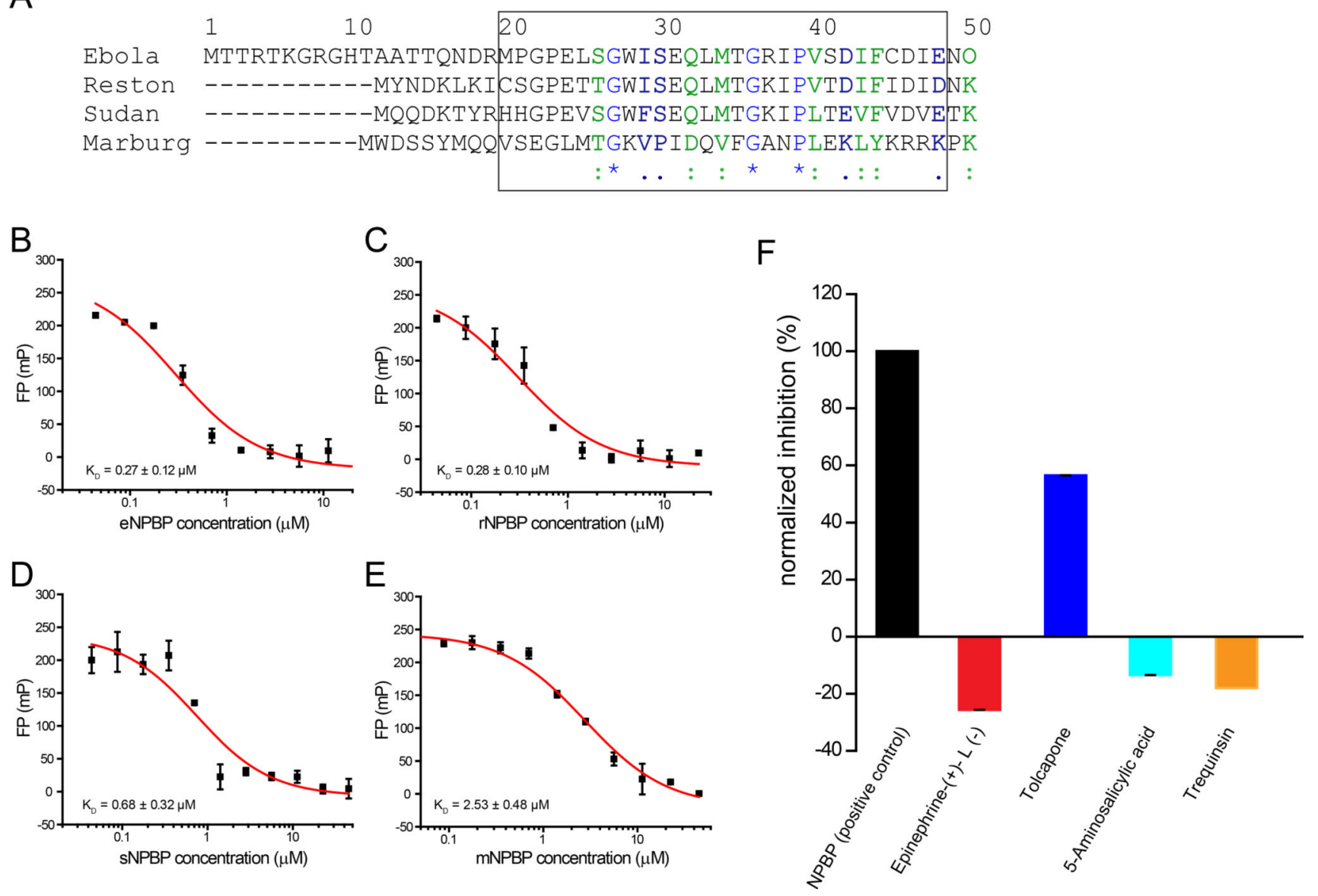

Figure 6.

EBOV NPBP/NP FP assay is a versatile panfiloviral assay that can function with NP proteins from all ebolaviruses and marburgviruses. (A) Multiple sequence alignment of the NPBP regions from Ebolavirus (accession AAQ55046), Restonvirus (accession AB050936.1), Sudanvirus (accession EU338380.1) and Marburgvirus (accession CAA78115) using ClustalW. Identical residues are shown in blue and labeled with '*'; strongly conserved in green and with ':'; and weakly conserved in dark blue and with '.'. FPA dose response curves for FITC-NPBP competition with corresponding NPBP sequences from (B) Ebolavirus (NPBP), (C) Restonvirus (rNPBP), (D) Sudanvirus (sNPBP), and (E) Marburgvirus (mNPBP). (F) Normalized BLI data for the competitors in B-E in Figure 5 using MARV NP as the protein receptor. $250 \mathrm{nM} \Delta \mathrm{NP}_{\mathrm{NTD}} \mathrm{mNP}_{\mathrm{NTD}}$ and $10 \mu \mathrm{M}$ competitor were used in the assays. 